\title{
Acute Esophageal Necrosis (Black Esophagus): Endoscopic and Histopathologic Appearance
}

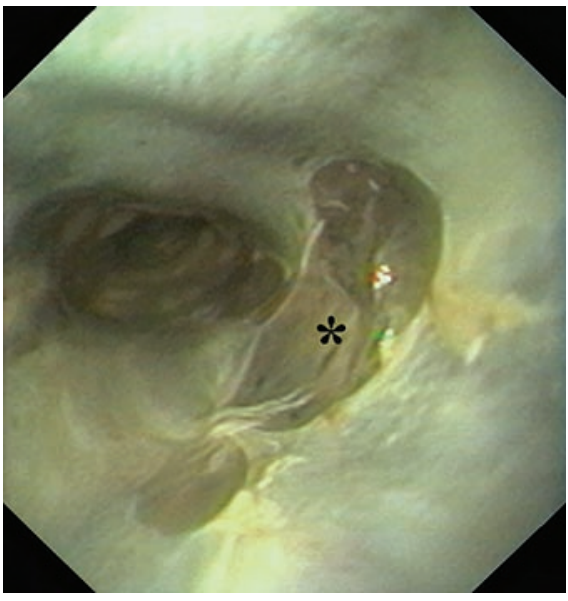

Figure 1 A 55-year-old woman in generally poor condition was admitted with life-threatening gastrointestinal bleeding. At endoscopy a dark diffuse black-greenish appearance was seen in the middle part of the esophagus. The necrotic esophageal mucosa was covered by pseudomembrane (asterisk) that could easily be removed by forceps.

\section{S. Rejchrt' ${ }^{1}$ T. Douda ${ }^{1}$, M. Kopáčová1,} M. Široký1', R. Repák' ${ }^{1}$ J. Nožička ${ }^{2}$, J. Špaček ${ }^{2}$ J. Bureš ${ }^{1}$

${ }^{1}$ Clinical Centre, Second Department of Medicine, Charles University Teaching Hospital, Hradec Králové, Czech Republic

${ }^{2}$ The Fingerland Institute of Pathology, Charles University Teaching Hospital, Hradec Králové, Czech Republic

\section{Corresponding Author}

\section{S. Rejchrt, M.D., Ph.D.}

Clinical Centre, Second Department of Medicine, Charles University Teaching Hospital

Sokolská 408

Hradec Králové

50005 Czech Republic

Fax: +420-495-832003

E-mail: rejchrt@lfhk.cuni.cz

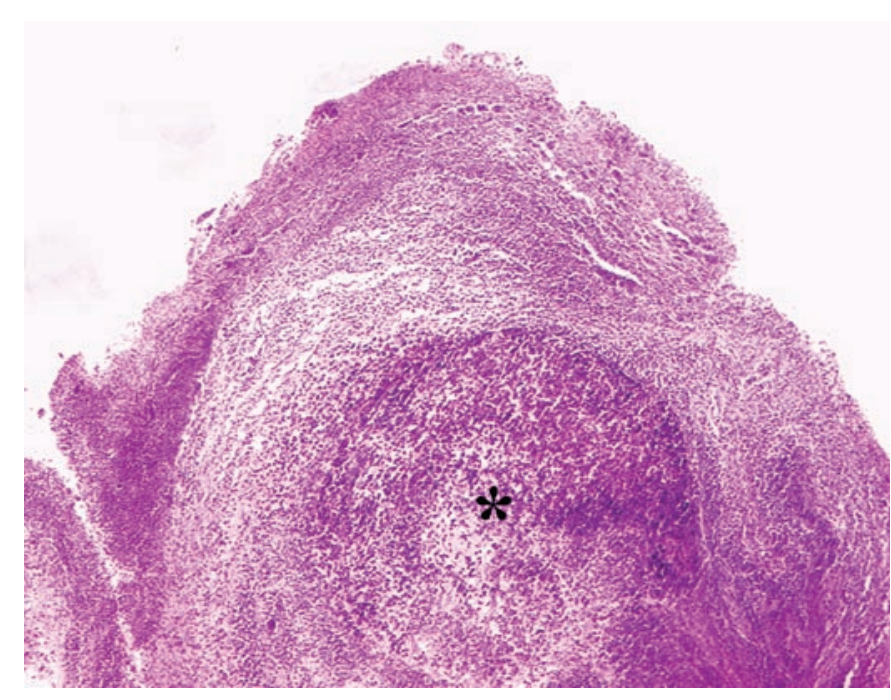

Figure 2 Mucosal and submucosal necrosis was found at histology (hematoxylin-eosin stain). Nonspecific granuloma was seen at the centre (asterisk).

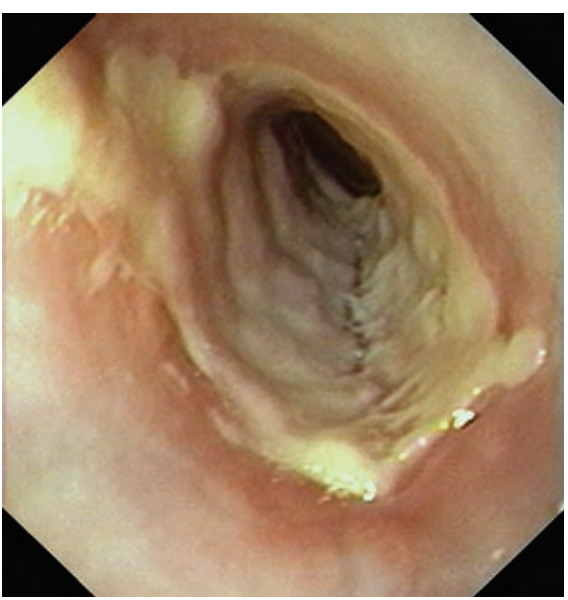

Figure 3 Appearance at control endoscopy after 3 months. Re-epithelialization had taken place in the proximal esophagus and circular ulceration covered with white fibrin was seen in the distal esophagus.

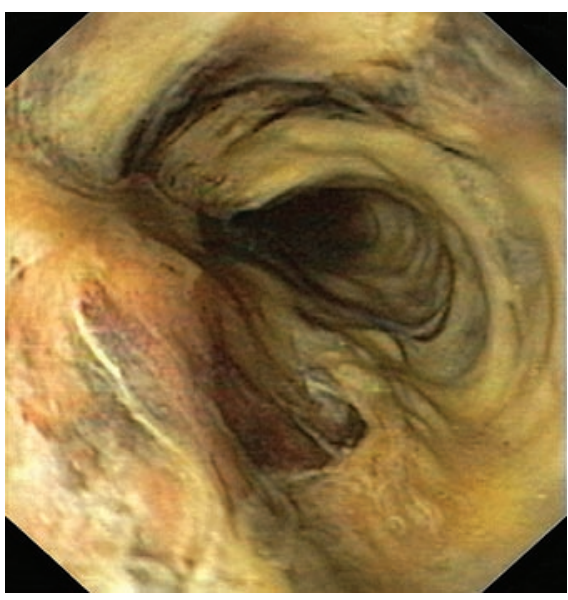

Figure 4 A 47-year-old man with relapse of cancer of the oral cavity. The patient was referred for percutaneous endoscopic gastrostomy (PEG) tube placement and an asymptomatic black esophagus was found. 